This is an electronic reprint of the original article. This reprint may differ from the original in pagination and typographic detail.

Author(s): Hännikäinen, Maritta

Title: $\quad$ The teacher's lap - a site of emotional well-being for the younger children in day-care groups

Year: $\quad 2015$

Version:

Please cite the original version:

Hännikäinen, M. (2015). The teacher's lap - a site of emotional well-being for the younger children in day-care groups. Early Child Development and Care, 185(5), 752765. https://doi.org/10.1080/03004430.2014.957690

All material supplied via JYX is protected by copyright and other intellectual property rights, and duplication or sale of all or part of any of the repository collections is not permitted, except that material may be duplicated by you for your research use or educational purposes in electronic or print form. You must obtain permission for any other use. Electronic or print copies may not be offered, whether for sale or otherwise to anyone who is not an authorised user. 


\title{
The teacher's lap - a site of emotional wellbeing for the younger children in day-care groups
}

\author{
Maritta Hännikäinen
}

Department of Education, University of Jyväskylä, PO Box 35, 40014, Jyväskylä

Finland

This study focuses on a particular relationship between teachers and one- to three-year-old children: the child in the teacher's lap. When, in what situations, does this happen? Who are the children in the teacher's lap? Why are they there? How do children express emotional wellbeing when in the teacher's lap? Relational, sociocultural and revised attachment approaches to emotional wellbeing supplied the theoretical framework of the study. Data were collected by ethnographic methods and analysed qualitatively. Two day-care groups in Finland participated. For most of the day at least one child was in a teacher's lap. The teacher's lap signified, e.g., consolation and confidence, but also delight. Further, for the children, it was a contested site for gaining teacher attention and displaying power. The teachers also enjoyed this affective bond with the children, while having a child in their lap also had practical value, e.g., sometimes it guaranteed undisturbed play for the other children.

Keywords: emotional wellbeing; day-care centre; early childhood education; one- to threeyear-old children

Sensitive, loving and caring relationships are crucial for the development and wellbeing of young children, including those in day-care groups. This small-scale study, as a part of a broader research project on the emotional wellbeing of young children in day-care centres, seeks to illuminate one specific manifestation of the mutual relationship between teachers and one- to three-year-old children: the child sitting or being held in the teacher's lap. The study asks: In what situations do children sit in the teacher's lap? Does every child need and also have equal access to the teacher's lap? What reasons might children and teachers have for seeking this kind of intimate relationship? The study also asks: In what ways is emotional wellbeing expressed in children, when picked up or 
held in the teacher's lap? The motive for the study is that, to the best of my knowledge, no research explicitly on this topic currently exists.

Overall, the project is designed to clarify and deepen our theoretical, methodological and empirical knowledge on the emotional wellbeing of young children. Its principal aim is to investigate emotional wellbeing in terms of children's participation and social relationships in day-care groups, and the ways in which teachers contribute to the children's wellbeing.

The project, and the study presented here, is grounded in knowledge synthesized from a variety of theories on learning and development. We know that a stimulating environment is important for a child's overall development (see cognitive, constructivist and co-constructivist approaches, e.g., Bruner et al., 1966; Piaget, 1929). We also know that education which is founded on an understanding of the child's need for security, connectedness and stable, intimate relationships with others, and which also appreciates and respects the child, is important for the way in which the child explores and constructs his or her world (see recent interpretations of the attachment theories, e.g., Ahnert et al., 2006; see also Hännikäinen, de Jong, \& Rubinstein Reich, 1997), and thus for the child’s emotional wellbeing. Further, the project draws on relational approaches in education (e.g., Hännikäinen \& Rautamies, 2008; Kutnick et al., 2008; see also Trevarthen, 2011), which also stress the importance of friendly and reciprocal interactions between the child and his or her caregiver. Moreover, the project lays emphasis on the sociocultural and activity theoretical approaches. As is well-known, these approaches posit that children develop relationships with other people through their activities, and that participation in social practices, interaction and collaboration are considered to be key factors in their social and cultural learning, meaning-making processes and wellbeing. The younger the child, the more tightly his or her activity is connected to mutual, emotional relationships with responsive 
adults, including with teachers in day-care groups (Elkonin, 1972; Leont’ev, 1978; Vygotsky, 1978; and more recently, see, e.g., Hedegaard \& Fleer, 2008; van Oers, 2012; Rogoff, 2003).

\section{Wellbeing and emotional wellbeing}

Since the turn of the millennium, increased attention has been paid to children's wellbeing in daycare centres and other early childhood contexts, both in the political and public arenas and in research. Wellbeing and its promotion are discussed and commented on in administrative and other documents relating to early childhood education, international surveys of children's wellbeing are carried out regularly, and indicators have been developed to measure, compare and assess wellbeing (OECD, 2011; UNICEF, 2007; see also Mashford-Scott, Church \& Tayler, 2012). In general, wellbeing is acknowledged as a children's right (United Nations, 1989). In early childhood education, wellbeing is also conceived as an educational aim; many studies have concluded that wellbeing has an important impact on children's behaviour in the classroom and their attitudes to learning, and hence also on their broader development and academic learning (see, e.g., MashfordScott, Church \& Tayler, 2012; Pinazza, 2012).

What, then, is wellbeing? Theoretically, no precise definition or operationalization of the notion of wellbeing or emotional wellbeing exists; the term remains open to different conceptualizations and methodological approaches (Barblett \& Maloney, 2010; Crivello, Camfield \& Woodhead, 2009; Mashford-Scott, Church \& Tayler, 2012). On a dictionary definition, wellbeing is “a feeling of being comfortable, healthy and happy” (Longman Dictionary of Contemporary English 2003, p. 1874). In the literature, wellbeing is commonly classified into economic, physical, social, cognitive and psychological domains (e.g., Bradford, 2012). The domain closest to the dictionary definition given above would appear to be that of psychological wellbeing, as a sense of agency, autonomy, competence, self-esteem, belonging, connectedness, social responsibility and the feeling of being 
valued seem to be considered its central characteristics (see Mashford-Scott, Church \& Tayler, 2012, p. 237).

The concept of emotional wellbeing (in particular) is often associated with psychological wellbeing: a person feels that his or her basic needs for safety, affection, social recognition and affirmation, feelings of competence, meaning in life and moral values are satisfied (Laevers, 2005, p. 8). According to UNICEF (2007, p.1), an important criterion of wellbeing among children is that they feel loved, safe and respected, as is also emphasized in the research literature (see Elfer, 2014). Emotional wellbeing is, without question, also related to social relationships and participation, whether the individual is an active agent in the social life processes of which he or she is part, or whether he or she is merely an object in processes determined by others (Hännikäinen et al., 1997).

In early childhood education, in both research and practice, the concept of emotional wellbeing is often taken for granted. In his work on the quality of education in day-care centres, Laevers (2005, p. 7) uses the metaphor "like a fish in water" to describe children's wellbeing, referring to children “who feel alright”. Children who feel alright give a relaxed impression, and they are self-confident and in touch with their emotions. Another sign of wellbeing is energy and vitality, which can often be read in children's faces: their look is lively and expressive. Moreover, according to Laevers, children's emotional wellbeing also manifests itself in an open attitude towards the surrounding world. The most obvious sign of wellbeing is enjoyment in activities and in interacting with others (Laevers 2005, pp. 7-8).

The characteristics of wellbeing described by Laevers refer to individual children, whether engaged in solitary or joint activities. These characteristics or manifestations of wellbeing are considered in this study per se, but they are also applied at the group level. However, given the theme of this 
study - the child in the teacher's lap -, the focus here is predominantly on individual wellbeing and the educational role of the teacher in this particular context.

Although empirical research on children's wellbeing in day-care centres is increasing, the studies on toddler groups are rare, and have often been conducted specially to measure and evaluate the quality of early childhood education settings. This also applies to the studies based on the views of Laevers and scales for assessing children's wellbeing, engagement and involvement developed by him and his colleagues (Laevers 2005; Laevers, Debruyckere, Silkens \& Snoeck 2005). Although these scales and studies cannot be utilized as a rigorous theoretical framework for this study, they nevertheless provide a useful conceptual foundation for exploring children’s emotional wellbeing in the teacher's lap.

\section{Social relationships between teachers and children}

The child sitting in the teacher's lap signifies a specific social relationship. Social relationships can be seen to have both objective and psychological components. The objective components comprise typical behaviours, interactions, and shared cultural practices. The psychological components consist of internal cognitive, motivational, and emotional states. At its best, the combination of these components results in a sense of reciprocity, intimacy, and commitment (Degotardi \& Pearson, 2009, p. 145). For young children, a safe, healthy and predictable environment - which also can be counted as an objective components of or prerequisites for social relationships, along with continuous and loving relationships with adults - enables positive experiences for their emotional wellbeing and personal growth (e.g., McMullen \& Dixon, 2009, p.116). 
The relationship between teacher and child manifests itself in verbal interaction, but it can also be seen in attitudes, eye contact, gaze, gestures, posture and touch (e.g., Brennan, 2007; Monaco \& Pontecorvo, 2010, p. 347). Verbal manifestations are not only about what teachers say, but also how they communicate with children: are they looking and listening with attention to what a child is saying, are they speaking in a friendly way, are they using respectful and responsive language? Non-verbal interaction can also be read in teachers' behaviour: are they offering comfort to a child, are they looking enthusiastic and interested in the child, are they showing enjoyment in their relationship with children? Are they sitting, kneeling or bending down to the children's level, and finally, do they create space for children to approach them and sit in their lap (Arnett, 1985-1986; Gloeckler, 2006, as cited in Dally et al., 2011, p. 83)? All in all, the central figure in developing positive social relationships between teacher and child and also between children, is the teacher, who is physically and emotionally present for the children by listening to them and orienting towards their experiences (e.g., Dalli et al., 2011: Ebbeck \& Yim, 2009).

For a child, it is important to have a feeling of togetherness and of belonging to the group. The way in which the teacher treats children, encourages children's participation and regulates the social relationships between them is without doubt connected to the teacher's educational practice. The teacher's role is also decisive in setting the group atmosphere. A warm and supportive atmosphere is acknowledged to have a strong impact on children's learning and wellbeing, and also on that of the teacher, as studies focusing on older children and teachers have explicitly shown (Jennings \& Greenberg, 2009; Skidmore, 2006).

\section{Method}


The project was carried out as a short-term qualitative case study (Yin, 2008) in two day-care groups in Finland. One group comprised 12 children and three teachers (exemplifying the more traditional model of a toddler group), while the other was a subgroup of eight children and two teachers drawn from a larger mixed-age group (exemplifying the increasingly prevalent small group pedagogy within a mixed-age group). The reason for including two groups in the project was to gain insight into the variation that exists in educational practices and group organization. In both groups, the teachers worked as a team, as is usual in Finland. In the traditional group, the core team comprised one college-educated kindergarten teacher and two day-care nurses, whereas in the mixed-aged group the core team comprised two day-care nurses (the day-care nurses had a vocational education of two or three years duration, depending on their year of qualification).

The data for the entire project were collected by applying an ethnographic approach. The main data collection methods were reactive observations (Corsaro, 2005; Hännikäinen, 2005), both with and without video recordings. The paper-and-pencil field notes were written in a free-flowing, narrative manner, i.e. everything that took place during the ongoing observation was documented. Sometimes the teacher was in the focus of observation, and sometimes an individual child, either alone or in a group, depending on the activity he or she was engaged in. Over the course of the observation period of four months each child in turn was the primary object of observation. The observation times were chosen to cover different activities throughout the day: free play activities, teacher-led structured activities and routine activities. In order to understand their motives and reasons for acting in certain ways, the teachers were group-interviewed using the method of stimulated recall. Four interviews, two with each day-care group, were arranged during the observation period. All the teachers participated. In addition to the scheduled interviews, the teachers could also express their thoughts at any time during encounters with the researchers. 
The interview themes were mainly derived from transcribed excerpts or video clips selected from the observations. In both groups, the themes concerned, for instance, the teachers' attitudes and beliefs regarding young children, their personal theories guiding their pedagogical work and their views on children's emotional wellbeing, including the role of the teacher's lap, as reflected in and compared to the practices described in the transcribed excerpts or viewed in the video clips. For the present study, however, the interview data and the data generated through the informal encounters were considered as supplementary material only, although also used as 'member checks' to add to the trustworthiness and credibility of the study.

The observations were carried out simultaneously by two researchers: the author and an assistant. Both are well-acquainted, theoretically and in professional practice, with early childhood education: both have been educated as kindergarten teachers and hold university degrees in education, and both have worked in day-care groups and have conducted scientific research in the field of early childhood education. Thus, the overall context of the study was familiar to both researchers.

Data were collected over four months. This relatively prolonged engagement with the children and teachers was essential for gathering an adequate body of research material, and hence supporting the trustworthiness of the study. In total, 18 visits were made to the groups, yielding 37 hours of documented observations. Transcribed, the observation data amounted to 235 text pages, of which 30 pages consisted of observations on 181 episodes where a child was sitting or being held in the teacher's lap.

The observation data were analysed by applying qualitative content analysis and microanalysis (e.g., Calais, 2008). The unit of analysis was a meaningful episode (i.e. an episode relevant to the theme, the teacher's lap). The length of individual episodes varied. Thus, a meaningful episode 
could be constituted by, e.g., a short verbal expression or action, or by a series of these. The interviews with the teachers were analysed thematically by using a data-driven approach.

The categories for the empirical data analysis emerged from the data in accordance with the theoretical and conceptual frame of the study and on the basis of earlier research findings. For instance, visible manifestations of emotional wellbeing (the child being relaxed, self-confidence, being in touch with his or her emotions, vitality and energy, openness and enjoyment) presented by Laevers (2005) were utilized per se with some additions, such as non-verbal expressions of togetherness by the children when engaged in shared activities. Thus, the concept of emotional wellbeing was empirically operationalized by means of these categories. Emotional wellbeing was also assessed and interpreted through subjective experiences of the researchers, described as attributes of the atmosphere, such as safe, supportive, warm, peaceful and quiet, energetic and joyful. However, many categories, such as the children's motives for being in the teacher's lap were identified inductively as data-driven categories. In sum, both the operationalization of the theoretical concepts and the analysis were abductive.

In addition to the data collection, the researchers also carried out the organization and analysis of the data collaboratively. Immediately after each visit to the day-care group, they compared and discussed their individual field notes in order to achieve shared understanding and joint interpretation of their observations, thereby producing a commonly agreed transcript on every observation day. Consensus was also sought in the analysis when coding and categorizing the data in accordance with the manifestations of emotional wellbeing. As the study focused on very young children, special attention was paid to interpretations of their non-verbal expressions. Although this collaborative procedure was considered necessary to enhance the trustworthiness and credibility of the study, it does not mean that the analysis is free from misinterpretations and other shortcomings. 
The observation data were analysed as a whole without between-groups comparisons. Authentic examples, excerpts from the observations, are taken from both groups; they are not intended as generalizable, but as illustrative examples of different situations. In the examples, the spoken language, Finnish, has been translated into English, and the names of the children, teachers and the settings have been changed. The Finnish pseudonyms have been translated to resemble international names to make it easier for the reader to identify the participant's gender and the course of events. The standard ethical principles and guidelines respecting good scientific practice (e.g., in addition to the preservation of anonymity, confidentiality, respect, and not harming the participants) have been followed throughout the project. An informed consent was given by the day-care personnel and parents; written assent could not be given by the children, owing to their very young age.

\section{Findings}

As mentioned above, 181 lap situations were noted during the observation period. However, it can be presumed that there were more, as the children were often divided and directed to different rooms in the centre, such as the group room, the play room, the gym, the place for water games and hallways, with one teacher in each, while the observations were carried out in just one room at a time. In both groups, there was almost always at least one child in the teacher's lap. Access to the teacher's lap was initiated equally by both children and teachers: in 79 cases the teacher took the initiative by picking the child up (carrying the child in her arms, sitting down with the child in her lap) and in 80 cases the child was the active partner, opening his or her arms and exhibiting the

desire to be taken into the lap, or just simply climbing into it. In 20 cases, the initiation of the situation passed unnoticed by the observers, and in two cases the child refused the proffered lap. 


\section{When and who in the lap?}

The teacher's lap was a pleasurable site for the children in the morning when they arrived: the parent passed the child to the teacher, or a child ran to the teacher who lifted him or her into her lap. In turn, when the teacher arrived at the centre later than the child, the child welcomed her by jumping into her lap. Likewise, some children wanted the lap at going home time; for others a warm hug was enough.

In fact, the teacher's lap was open to the children throughout the day. Children sat in the teacher's lap during routine situations, such as dressing and undressing or having lunch, during structured activities, such as circle time and small assemblies, and during free activities, such as play and exploration. The teacher's lap was also a place to jump in and out of during rough and tumble games. There were also 'ritualized lap times', such as contact games during assemblies before lunch and individual moments before nap time. These practices guaranteed every child an opportunity to be in the teacher's lap: no child refused the ritual. In the interviews, the teachers referred to these moments playfully as ‘compulsory lap time’.

Every child had access to and was held in the teacher's lap at some point during the observation period, also outside the 'ritualized lap times'. However, some children were more often in the teacher's lap than other children. Sometimes a child just entered the lap all of a sudden in the midst of play, but the younger the children were, the more often they entered and the longer the time they spent in the lap, for instance it could last throughout the lunch break or a music session. Newcomers, who were also the youngest in both groups, spent most of their first day-care days in the teacher's lap. There were also differences between the older children, as one teacher put it in an interview: “There are 'lap sitters' in the group, and there are children who don’t like sitting in the 
lap that much”. Girls indicated their wish to be taken into the lap more often than boys, and the teachers also tended to pick up girls more often than boys.

Very often the lap was shared by two or three children, which the teachers noted by expressions like "Really, one should be an octopus" or "Fortunately, we have two knees". Occasionally, the teacher's lap was a contested site for the children. This was the case when another child wanted to join the incumbent by claiming "Me too", or one child did not want to share with another child, as indicated by stating "My place” or "Just me”. There were also situations when a child lost his or her place in the teacher's lap, such as when the teacher had to lay the child down because she was needed elsewhere to take care of another child or help with practical arrangements.

\section{Why in the lap?}

Owing to their age and limited verbal skills, the youngest children in the group mainly used gestures, postures and vocalizations to express their motives or needs for the lap instead of spoken language that would be readily comprehensible to the teachers or researcher. Thus, the answers to the question why children want to sit in the teacher's lap are to great extent based on the immediate event or situation and interpretation of behavioural clues. It goes without saying that the same applies to the children's manifestation of lap-related emotional wellbeing.

The situations in which the child was active and took the initiative to be picked up or climbed into the teacher's lap were categorized into five groups of assumed motives: seeking proximity and an affective bond, safety and protection; experiencing delight at seeing the teacher; seeking individual attention or acknowledgement; enjoyment of 'rough' tenderness; and seeking consolation because 
of being pushed over or excluded from play by another child. These motives were not mutually exclusive and some of them occurred simultaneously.

The children seemed most often to seek proximity and an affective bond, safety and protection. These moments were particularly evident in the morning, when the child was still pining for his or her parent, but they could also occur any time during the day. The motives of the teachers in taking the child into their lap were twofold. On the one hand, they were aligned with the children's motives: enjoying an affective bond with the child, offering proximity, safety and protection; paying individual attention to and acknowledging the child; and affording consolation on various occasions. On the other hand, they had to do with basic care and various practical matters, such as lifting a child into a highchair, helping a child to reach a thing or place, providing physical safety, solving a dispute or calming the child or things down. The most common reasons for having a child in one’s lap were linked with basic care: the children were fed in the lap, dressed in the lap or had their hands and faces washed in the lap. The frequencies of the different motives of the children for seeking and teachers for providing the lap are presented in table 1:

(Table 1 approximately here)

Below, some authentic examples of both child-initiated and teacher-initiated lap situations are described and analysed from two viewpoints: “why is the child in the teacher's lap?" and manifestations of emotional wellbeing. The examples are taken from children's free activities, 
routine activities and teacher-led small assemblies. The first example illustrates a typical situation during play time.

MARIA (teacher) is sitting on the floor. Mia (1:5) comes over and sits in her lap. Mia gets up right away and goes off to look at two older girls engaged in role play.

Natalie (1:8) comes and sits in MARIA's lap. Mia comes back and seats herself in MARIA's lap beside Natalie.

Natalie leaves MARIA’s lap to play with toy cars.

A few seconds later, Mia also leaves MARIA's lap, but soon returns soon and again leaves. She goes over to the home corner and turns the knobs on the play cooker while watching Natalie’s car game. She then returns to MARIA’s lap.

MARIA puts Mia down in order to pick Ida (1:4) up from the entrance hall. MARIA carries Ida into the room while Mia looks on attentively. MARIA puts Ida down, and Ida goes off to look at the older girls' role play.

Mia sits down in MARIA's lap. She immediately leaves, but soon returns. Natalie comes over, stands beside Mia and then hits Mia with a Dublo block and shoves her aside, but does not sit down in MARIA's lap.

Mia cries “Ow!”, and begins walking over to the home corner.

MARIA: “Are you going to do some cooking?”

Mia goes to investigate play dishes on the table.

The starting situation was characteristic of day-care centres for younger children: in both groups the teachers were often close to the children, sitting on the floor or on a couch, and thus easy for the children to reach. Here too, Mia, who is close to the teacher, notices her on the floor and sits down in her lap. Mia might have a need for proximity, however, it is enough for the present just to pop 
into the teacher's lap. Other things going on around her are also of interest. Perhaps Natalie has noticed Mia in the teacher's lap, and gets the idea of doing the same thing. Mia who has been nearby, looks at the teacher and Natalie and decides to return to the teacher's lap. There is room for two, but Natalie steps aside and starts playing next to the teacher and Mia. Mia leaves the teacher's lap and returns after the teacher has picked Ida up from the entrance. By coming and going Mia might be seeking a feeling of security.

Natalie follows the situation and seems not to be happy seeing Mia in the teacher's lap, and her reaction, hitting Mia, could be interpreted as kind of envy. The teacher does not intervene in the incident but pays special attention to Mia by asking about her intentions. Considering the duration of the entire situation, Ida has a minor role. However, since she has just arrived and been carried into the room in the teacher's lap, she gets the teacher's individual attention for a while. Although the situation is one of constant movement, the atmosphere is quiet and warm, signalling the emotional wellbeing of all the participants. The only rift is caused by the small incident between Natalie and Mia.

The next episode is from a routine situation. Play time is over and it is time to for outdoor activities. There are one teacher and three children in the entrance hall, while the other children in the group are either in the group rooms or already outdoors with the other two teachers.

JENNY (teacher), sitting on a bench, has lifted Natalie (1:8) into her lap and is dressing her. Mia (1:5) is standing next to them on the floor. She vocalizes something and looks at JENNY.

JENNY: "You'd like to go out? Of course you can go out." 
When Natalie has got dressed, JENNY hugs her and carries her into the outdoor hall, Natalie wearing a pleased look. Then JENNY then lifts Mia into her lap and begins to dress her. Mia appears content.

Sometimes the children were on the floor trying to dress or undress on their own, but in most cases the teacher dressed or helped the child while keeping him or her in her lap. Thus, when dressing Natalie and Mia here, one of the teacher's motives is doubtless practical, and linked to basic care. At the same time she pays individual attention to both children. With Natalie, the teacher also shows her affective bond and tenderness by giving her a warm hug. Mia waits patiently for her turn, and then draws the teacher's attention to herself both verbally and by gaze. The teacher listens to Mia and interprets her message as a wish or a reminder that she too would like to go out. The fact that both children appear relaxed and satisfied can be interpreted as a sign that their needs had been taken seriously, and thus as a manifestation of their positive emotional wellbeing. The atmosphere is peaceful.

The next example also centres on a routine situation, but here the initiative is taken by the child. It is early in the morning.

MARIA is pushing the breakfast trolley into the group room. Anna (1:0) toddles over to MARIA and holds out her arms to her.

MARIA stops, looks at Anna and says in a friendly voice: “MARIA can’t pick you up now, so Anna, just hold onto the trolley here [shows].”

Anna does not hold onto the trolley but continues holding out her arms. MARIA lifts her up and continues to push the trolley with one hand. Anna looks satisfied. 
Anna is a newcomer at the day-care centre, and has spent only a couple of weeks in the group. She is already acquainted with the three teachers and attached to them, but frequently expresses her need for safety and proximity. This episode is a representative of it. Her emotional wellbeing is an outcome of her persistence; she does not give up her wish to be picked up and held in the lap. Her success can be observed in her face.

The following excerpt illustrates a teacher-led assembly. The whole group of eight children have just returned from visiting a play park. The one-year-olds are already having lunch with one teacher in the group room. The older children are sitting on the L-shaped couch in the next room. The teacher is sitting in front of them on a chair.

HELEN (teacher): "We have just seen little birds in the park. Who would like to be the first to be sung to about the little bird?”

Emma (2:4) eagerly: “Me.”

HELEN opens her arms: “So, come here!”

HELEN lifts Emma into her lap and sings while bouncing Emma in her lap: “A little bird jumped, a little bird jumped like this...run along, you can go eat.”

HELEN hugs Emma warmly. Emma smiles, steps down and goes off for her lunch. William (2:2) hurries to HELEN.

HELEN: “Are you going to be next, William?”

HELEN sings and bounces William in her lap. William smiles, and when he is hugged looks very happy.

The assembly ends when every child has been sung to about the little bird. 
The tradition in the group is that while the younger children are having lunch, a small assembly for singing and rhyming is held for the two- to three-year-olds. As a rule, the children leave the assembly one at a time, accompanied, for instance, by a song. The practical motive for the teachers in arranging gatherings like this is to ensure a peaceful lunch break first for the younger children, and then for the older ones. There are, however, other motives too. The assembly offers the teacher an opportunity to pay individual attention and afford pleasure to each child in turn. The teacher is physically and emotionally present, the atmosphere is warm and every child is involved in this “ritualized lap time” with its vitality, energy and enjoyment, expressing togetherness with each other and with the teacher.

The final excerpt illustrates a rather typical situation during the morning session after breakfast. The teacher is sitting on the floor and the children are nearby. Some are playing, others wandering from place to place and watching what is going on. Victor has been playing a bit further away, but when he looks at the teacher he gets an idea:

Victor (2:4) runs to hug HANNA (teacher). He then wraps his arms wildly around her. She smiles and picks Victor up in her lap and begins to cradle him in her arms.

HANNA sings a lullaby: “Aa tuuti Victor...”

Victor and HANNA look into each other's eyes and laugh.

Emma (2:5) standing beside them: “[Now] to me!”

HANNA: “Aa tuuti, or?”

Emma climbs into HANNA's lap, while Victor and Sylvie (2:3) cling to HANNA's neck. The children laugh.

HANNA clasps Emma in her arms and sings, patting Emma gently, “Aa tuuti Emma...” 
The excerpt exemplifies the children's ways of expressing themselves in boisterous play, in which they invite their teachers to join, and the ways in which the teachers respond to such invitations. The initiative comes from Victor, but the catalyst is the teacher, who is physically close and emotionally available to the children. Victor displays delight at recognizing the teacher and expresses his affective bond with her. The teacher immediately responds to his direct physical signal to be taken into her lap. However, she makes a gentle joke of the situation by singing a lullaby to Victor as if he were a baby. This funny situation attracts Emma's attention and she decides she too would like the same as Victor. Sylvie also shows interest in what is happening, which then culminates in a display of rough tenderness and a kind of boisterous play. The situation manifests fascination, vitality and happiness. All the participants are fully and enthusiastically involved and the atmosphere is energetic and joyful.

\section{Discussion}

In a study by Einarsdottir (2011, p. 394), a group of first-graders were interviewed about their preschool experiences, and asked, for instance, when they had felt safe in preschool. Several children reported they had felt safe when the teacher was around, and one child specified: “In the teacher's lap.” In the present study, due to the children's young age, their experiences of safety could not be examined by means of an interview or discussion. However, the observations clearly demonstrated that the teacher's lap, and the affective bond it signifies between lap-giver and child, was experienced by the young children as a site of safety. The children most often seemed to seek

proximity, security and protection (see Ahnert et al., 2006), when indicating their desire for the teacher’s lap. 
Arrival times were lap-seeking times for most children, and many children left for home via the teacher's lap. In fact, the teacher's lap was available for the children at all times of the day, including during routine situations, structured activities and free activities. There were also different 'ritualized lap times' when each child in turn was taken into the teacher's lap. Most of the day at least one child was in the lap of one or other of the teachers. The youngest children in particular spent a considerable amount of time in the teacher's lap. It was also common for children to pop in and out of the teacher's lap, thus using her as a secure base before returning to their own activities an observation also made by Gloeckler and Niemeyer (2010).

In addition to safety, security and proximity, the teacher's lap also signified, for instance, confidence and consolation, and delight and joy (cf. Arnett, 1985-1986; Gloeckler, 2006). Further, it was a contested site for gaining teacher attention and displaying power. The teachers in turn also enjoyed their affective bond with the children; however, having a child in their lap also had practical value, such as guaranteeing undisturbed play for the other children.

The presence of an affective bond and friendly, reciprocal interactions between teacher and child, signalling shared understanding and emotional closeness (see e.g., Trevarthen, 2011), was regularly observed. When holding a child in their lap, the teachers displayed a caring attitude and love (Brennan, 2007) by touching warmly, caressing, kissing, hugging and embracing the child. The safe and warm atmosphere created in such situations in turn encouraged the children to express their attachment and tenderness towards each other as well as to the teacher (cf. Ahnert et al., 2006; Hyson \& Taylor, 2011). Hence, on occasions like this we could speak of learning through intent participation and imitation (Rogoff, 2003). 
The teacher's lap was an important place for “academic learning” as well: in the teacher's lap, the children could enhance their knowledge of the world, practice their language skills and learn the rudiments of mathematics through songs, rhymes and stories. Reading to children and looking at picture books with them was one of the everyday activities during which children would most obviously sit in the teacher's lap. A very convenient place for joint reading was the L-shaped couch where the teacher sat in the corner with one or two children in her lap and two or three children on each side. In this way, all the participants were able not only to feel belongingness to the group (Eaude, 2009) and experience togetherness (Hännikäinen, 1999), but also to see the pictures and hear the teacher's and each other's voices and so communicate about the book. Thus, joint reading linked cognition and emotion together, which is an unconditional prerequisite for meaningful learning (Vygotsky, 1987).

In addition to cognitive learning, a warm, mutual relationship between teacher and child is connected to a several other domains of the child's development and learning, such as self-esteem, self-confidence and self-regulation, positive communication, understanding other people and moral understanding (Adams, 2011; Cheshire, 2007). It would seem clear that the teacher's lap, as observed in this study, signified such a relationship.

In this study, the concept of emotional wellbeing was understood by reference to the metaphor "like a fish in water” (Laevers, 2005, p. 7). Yet, at the same time, the concept was used, both theoretically and empirically, in a restricted way, as the analysis and interpretations were mainly based on visible signs of wellbeing only (Laevers, 2005). In light of this limited conceptualization, the present findings indicate a number of good practices based on a sensitive, loving and caring relationship actualized in their laps, through which teachers can promote children's learning, development and wellbeing. These practices include, for instance, being physically and emotionally 
present and available, communicating in a friendly way, being attentive, showing interest in and recognition of the children, reacting on to their intentions and offering them agreeable experiences. In these ways, teachers can contribute to young children's happiness and quality of life (Axford, 2008; Ben-Arieh \& Frønes, 2011) and, finally, help them to enjoy a good life in day-care groups.

\section{Acknowledgements}

This work was supported by the Academy of Finland under Grant number 136200.

Warm thanks to M.Ed. Kati Hemminki for her assistance in collecting, organizing and analysing of the literature and empirical data.

\section{References}

Adams, E.J. (2011). Teaching children to name their feelings. Young Children, 66 (3), 66-67.

Ahnert, L., Pinquart, M., \& Lamb, M. E. (2006). Security of children's relationships with nonparental care providers. A meta-analysis. Child Development, 77, 664-679.

Arnett, J. (1985-1986). Caregiver Interaction Scale. Princeton, NJ: Educational Testing Service.

Axford, N. (2008). Exploring concepts of child well-being: Implications for children's services. Bristol: Policy Press.

Barblett, L., \& Maloney, C. (2010). Complexities of assessing social and emotional competence and wellbeing in young children. Australasian Journal of Early Childhood, 35 (2), 13-18.

Ben-Arieh, A., \& Frønes, I. (2011). Taxonomy for child well-being indicators: A framework for the analysis of the well-being of children. Childhood, 18, 460-476. 
Bradford, H. (2012). The wellbeing of children under three. London and New York: Routledge.

Brennan, M. (2007). A culture of tenderness: teachers' socialization practices in group care settings. European Early Childhood Education Research Journal, 15, 137-146.

Bruner. J.S., Oliver, R.R., \& Grenfield, P.M. (1966). Studies in cognitive growth. New York: Wiley.

Calais, G. J. (2008). Microgenetic analysis of learning: Measuring change as it occurs. National Forum of Applied Educational Research Journal 21 (3), 1-7.

Cheshire, N. (2007). The 3 R's: Gateway to infant and toddler learning. Dimensions of Early Childhood, 35 (3), 36-38.

Corsaro, W. (2005). The sociology of childhood ( $2^{\text {nd }}$ ed.). Thousand Oaks: Pine Forge Press.

Crivello, G., Camfield, L., \& Woodhead, M. (2009). How can children tell us about their wellbeing? Exploring the potential of participatory research approaches within young lives. Social Indicators Research, 90 (1), 51-72.

Dalli, C., White, E.J., Rockel, J., Duhn, I., with Buchanan, E., Davidson, S., ...Wang, B. (2011). Quality early childhood education for under-two-year-olds: What should it look like? A literature review. Ministry of Education, New Zealand. Retrieved from

http://www.educationcounts.govt.nz/_data/assets/pdf_file/0009/89532/965_QualityECE_Web22032011.pdf

Degotardi, S., \& Pearson, E. (2009). Relationship theory in the nursery: attachment and beyond. Contemporary Issues in Early Childhood, 10, 144-155.

Eaude, T. (2009). Happiness, emotional well-being and mental health - what has children's spirituality to offer? International Journal of Children's Spirituality, 14 (3), 185-196. 
Ebbeck, M., \& Yim, H.Y.B. (2009). Rethinking attachment: fostering positive relationships between infants, toddlers and their primary caregivers. Early Child Development and Care, 179, 899-909.

Einarsdottir, J. (2011). Reconstructing playschool experiences. European Early Childhood Education Research Journal, 19, 387-402.

Elfer, P. (2014). Facilitating intimate and thoughtful attention to infants and toddlers in nursery. In L. J. Harrison, \& J. Sumsion (Eds.), Lived spaces of infant-toddler education and care: Exploring diverse perspectives on theory, research and practice (pp. 103-117). Dordrecht, Heidelberg, New York, London: Springer.

Elkonin, D. B. (1972). Towards the problem of stages in the mental development of the child. Soviet Psychology, 10 , 225-251.

Gloeckler, L. (2006). Teacher/caregiver practices influencing the early development of emotion regulation in toddlers (Unpublished $\mathrm{PhD}$ thesis). University of North Carolina at Greensboro, USA.

Gloeckler, L., \& Niemeyer, J. (2010). Social-Emotional Environments: Teacher Practices in Two Toddler Classrooms. Early Childhood Research \& Practice. 12 (1), 9. Retrieved from http://ecrp.uiuc.edu/v12n1/gloeckler.html

Hedegaard, M., \& Fleer, M. (2008). Studying children: A cultural-historical approach. Maidenhead, Berkshire: Open University Press.

Hyson, M., \& Taylor, J. (2011). Caring about caring: What adults can do to promote young children's prosocial skills. Young Children, 66 (4), 74-83.

Hännikäinen, M. (1999). Togetherness - a manifestation of preschool life. Early Child Development and Care, 151, 19-28.

Hännikäinen, M. (2005). Rules and agreements - and becoming a preschool community of learners. European Early Childhood Education Research Journal, 13, 97-109. 
Hännikäinen, M., de Jong, M., \& Rubinstein-Reich, L. (1997). "Our heads are the same size" A study of quality of the child's life in Nordic day care centres. University of Lund, Malmö School of Education. Department of Educational and Psychological Research. Educational information and debate 107.

Hännikäinen, M., \& Rautamies, E. (2008). Developing good practice in Finnish day care centres: Focus on relationships and interaction. In P. Kutnick, M.L. Genta, A. Brighi, \& A. Sansavili (Eds), Relational approaches in early education: Enhancing social inclusion, and personal growth for learning (pp. 144-176). Bologna: CLUEB.

Jennings, P., \& Greenberg, M.T. (2009). The prosocial classroom: Teacher's social and emotional competence in relation to student and classroom outcomes. Review of Educational Research, 79, 491-525.

Kutnick, P., Genta, M.L., Brighi, A., \& Sansavili, A. (Eds.). (2008). Relational approaches in early education: Enhancing social inclusion, and personal growth for learning. Bologna: CLUEB.

Laevers, F. (Ed.). (2005). Well-being and involvement in care settings. A process-oriented selfevaluation instrument. Leuwen: Kind \& Gezin and Research Center for Experiential Education.

Laevers, F., Debruykere, G., Silens, K., \& Snoeck, G. (2005). Observation of well-being and involvement in babies and toddlers. A video-training pack with manual. Leuven: Research Centre for Experiential Education.

Leont'ev, A. N. (1978). Activity, consciousness, personality. Englewood Cliffs, N.J.: Prentice Hall.

Longman Dictionary of Contemporary English (new ed.) (2003). Harlow: Pearson Education Limited.

Mashford-Scott, A., Church, A., \& Tayler, C. (2012). Seeking children's perspectives on their wellbeing in early childhood setting. International Journal of Early Childhood, 44, 231-247

McMullen, M., \& Dixon, S. (2009). In support of a relationship-based approach to practice with infants and toddlers in the United States. In D. Berthelsen, J. Brownlee, \& E. Johansson (Eds.), 
Participatory learning in the early years; research and pedagogy (pp. 109-128). New York, London: Taylor \& Francis.

Monaco, C., \& Pontecorvo, C. (2010). The interaction between young toddlers: constructing and organizing participation frameworks. European Early Childhood Education Research Journal, 18, 341-371.

OECD. (2011). How is life? Measuring well-being. Paris: OECD.

van Oers, B. (Ed.). (2012). Developmental education for young children: Concept, practice and implication. Dortrecht, Heidelberg, New York, London: Springer.

Piaget, J. (1929). The child's conception of the world. New York: Harcourt \& Brace.

Pinazza, M. (2012). The right of young children to well-being: a case study of a crèche in Portugal. European Early Childhood Education Research Journal, 20, 577-590.

Rogoff, B. (2003). The cultural nature of human development. Oxford: Oxford University Press.

Skidmore, D. (2006) Pedagogy and dialogue. Cambridge Journal of Education, 36, 503-514.

Trevarthen, C. (2011). What young children give to their learning, making education work to sustain a community and its culture. European Early Childhood Education Research Journal 19, 173-193.

United Nations. (1989). Convention on the Rights of the Child. Geneva: Office of the United Nations High Commissioner for Human Rights.

UNICEF. (2007). Child poverty in perspective: An overview of child well-being in rich countries. Innocent Report Card 7. Florence: UNICEF Innocenti Research Centre.

Vygotsky, L.S. (1978). Interaction between learning and development. In M. Cole, V. John-Steiner, S. Scribner, \& E. Souberman (Eds.), Mind in society: The development of higher psychological processes (pp. 79-91). Cambridge: Harvard University Press. 
Vygotsky, L.S. (1987). Thinking and speech. In R.W. Rieber, \& A. S. Carton (Eds.), The collected works of L.S. Vygotsky (Vol.1. Problems of general psychology, pp. 39-285). New York and London: Plenum Press.

Yin, R.K. (1998). Case study research (4th ed.). Los Angeles, London, New Delhi, Singapore, Washington DC: Sage. 
Table 1. Motives for accessing the teacher's lap

Child-initiated (80 incidents)

Seeking proximity, an affective bond, safety and protection

63

Experiencing delight at seeing the teacher

6

Seeking individual attention or acknowledgement 5

Enjoying 'rough' tenderness 4

Seeking consolation 2

Teacher-initiated (79 incidents)

$\begin{array}{ll}\text { Basic care-giving } & 21\end{array}$

Proximity, enjoying an affective bond 14

Paying individual attention, acknowledging 11

Offering consolation $\quad 9$

Helping to reaching a place/thing $\quad 9$

Providing physical safety 6

Solving a dispute, calming the child or things down 6

Securing undisturbed play 3 